\title{
Treatment of corticosteroid-refractory new onset systemic lupus erythematosus in pregnancy with plasmapheresis and immunoadsorption
}

\author{
Boedecker S, Macchiella D, Ahlbrand C, Schwarting A and Weinmann-Menke J* \\ Department of Medicine, Department of Gynaecology, Medical Center of the Johannes Gutenberg-University, Mainz, Germany
}

\begin{abstract}
Primary manifestation of Systemic lupus erythematosus (SLE) can be induced by pregnancy. Disease development and cytostatic therapy may affect gestation, but disease can be refractory to the less toxic corticosteroid therapy.

We present the case of a 24 year-old pregnant women with primary manifestation of SLE in the $24^{\text {th }}$ gestation week (nephritis, pericarditis, fever, splenomegaly and arthritis). High doses of prednisolone only led to a moderate relief of her severe symptoms, and disease activity (high serum levels of anti-ds-DNA antibodies, low serum levels of $\mathrm{C} 3 \mathrm{c} / \mathrm{C} 4$, nephritic syndrome) remained unchanged. Therefore, plasmapheresis therapy was started and resulted in an amelioration of disease activity and symptoms. After reduction of immunocomplexes by plasmapheresis, it was possible to continue therapy with immunoadsorption to limit the exposure to donor plasma. Under immunoadsorption clinical symptoms and laboratory parameters normalized, and the preterm delivery of a healthy child in the $28^{\text {th }}$ gestation week was without any complications. Our observations as well as previous reports suggest immunoadsorption as a well-tolerated "rescue-therapy" in pregnant patients with highly active SLE.
\end{abstract}

\section{Introduction}

Systemic lupus erythematosus (SLE) is a spontaneous systemic autoimmune disease that injures multiple organ systems and has several and highly variable clinical manifestations, such as polyarthritis, nephritis, pericarditis or erythema. Characteristic features in SLE are production of autoantibodies, especially against nuclear constituents, the resulting formation of immune complexes, and deposition of immune complexes in several tissues (like glomeruli, lung, skin, synovia, or mesothelium), which may lead to different clinical manifestation of SLE. According to the affected tissue, skin rash and joint pain can be predominate findings in some patients, while in others SLE primarily leads to severe kidney disease (glomerulonephritis), which existence is highly relevant for morbidity and mortality in SLE patients [1-3]. SLE occurs especially in women at the age of 20 to 40 years. Although the immunological processes leading to onset and maintenance of SLE are incompletely understood, there is evidence for its multifactorial aetiology, involving environmental, hormonal and genetic factors. $\mathrm{T}$ - and B-cells, dendritic cells and cytokines seem to play major roles in the pathogenesis of SLE [4-6]. It is recognized that pregnancy can trigger primary manifestation of SLE. Patients with SLE and progressive renal failure or other major organ involvement need aggressive immunosuppressive therapy with corticosteroids and cytotoxic agents $[7,8]$, but cytotoxic therapy affects gestation. Treatment with corticosteroids may be efficient in pregnancy-induced SLE, but disease can be refractory to corticosteroids. In these cases, the elimination of auto-antibodies and immune-complexes by plasmapheresis and immunoadsorption might efficiently decrease disease activity and improve foetal survival [9].

\section{Case report}

A 24-year old pregnant woman ( $4^{\text {th }}$ pregnancy, $24^{\text {th }}$ gestation week) was diagnosed having pregnancy-induced primary manifestation of SLE, according to the American College of Rheumatology 1997 revised criteria. She already had two healthy children, both pregnancies succeeded without any complications, the healthy babies were born at gestation week 39 respectively $39+2$ with normal birth weight, but a third pregnancy in 2001 resulted in an intra-uterine foetal death.

Clinically, the patient presented polyarthritis, pericarditis, nephritis with hypertension, splenomegaly, and pancytopenia, so far growth of the foetus was confirmed to be normal ( $24^{\text {th }}$ gestational week). She was tested positive for anti-nuclear antibodies (ANA) and anti-doublestranded DNA (anti-ds DNA) antibodies. Anti-SSA/Ro, antiSSB/La and anti-cardiolipin IgG/IgM antibodies were negative, CD4/CD8 ratio and serum level of IgG were within the normal range. Initial serum level of anti-dsDNA antibodies was $>200 \mathrm{IU} / \mathrm{ml}$ [reference $<35$ I U/ $\mathrm{ml}]$, and the serum levels of complement factors $\mathrm{C} 3 \mathrm{c}$ and $\mathrm{C} 4$ were low (C3c 0.41 g/l [reference 0.9-1.8 g/l] , C4 <0.06g/l [reference 0.1-0.4 g/l]). Autoimmune haemolysis resulted in distinct anaemia (haemoglobin $6.4 \mathrm{~g} / \mathrm{dl}$ [reference $12-16 \mathrm{~g} / \mathrm{dl}])$. Urinalysis revealed a non-selective glomerular proteinuria $(1340 \mathrm{mg} / 24 \mathrm{~h}$ [reference: $6.8 \mathrm{mg} / 24 \mathrm{~h}$ ]) and

*Correspondence to: Weinmann-Menke J, Department of Medicine, Medical Center of the Johannes Gutenberg-University, Mainz, Germany, Tel: 496131176774; Fax: 496131178471; Email: Julia.weinmann-menke@ unimedizin-mainz.de

Received: December 12, 2018; Accepted: December 28, 2018; Published: December 31, 2018 
glomerular haematuria $(6.4 \%$ acanthocytes [reference: $<5 \%])$, resulting from glomerular affection, serum creatinine was $0.53 \mathrm{mg} / \mathrm{dl}$ [reference 0.5 $0.9 \mathrm{mg} / \mathrm{dl}$ ], creatinine clearance $115.3 \mathrm{ml} / \mathrm{min}$ [reference $70-140 \mathrm{ml} / \mathrm{min}$ ].

First, the patient was treated with $250 \mathrm{mg}$ prednisolone/day, daily dose was increased up to $1000 \mathrm{mg}$ /day when the patient did not respond to lower doses and developed signs of pre-eclampsia. Hypertension was successfully treated with alpha-methyldopa and metoprolol. High-dose steroid therapy for 8 days only led to a moderate amelioration of the symptoms, markers of disease activity $(\mathrm{C} 3 \mathrm{c} / \mathrm{C} 4$, anti-dsDNA antibodies, proteinuria and glomerular haematuria) nearly remained unchanged $(\mathrm{C} 3 \mathrm{c}$ $0.54 \mathrm{~g} / \mathrm{l} ; \mathrm{C} 40.07 \mathrm{~g} / \mathrm{l}$; anti-dsDNA antibodies $>200 \mathrm{IU} / \mathrm{ml}$ ).

Since high-dose treatment with glucocorticoids did not alleviate the activity of disease sufficiently, we initiated plasmapheresis, eight times at intervals of one to two days. Plasmapheresis was carried out with the continuous flow system "Cobe Spectra" (Gambro), applying the program "TPE" (therapeutic plasma exchange). Eliminated plasma was substituted with fresh frozen plasma (mean volume: $2950 \mathrm{ml} / \mathrm{session}$ ). After the second plasmapheresis treatment the patient felt a significant improvement of her arthritic symptoms, and her general health condition further recovered from treatment to treatment. Haemoglobin was stabilised between 9 and $11 \mathrm{~g} / \mathrm{dl}$ after administration of six red blood cells concentrates. After eight treatments, anti-dsDNA antibodies decreased to $169.2 \mathrm{IU} / \mathrm{ml}$, and $\mathrm{C} 3 \mathrm{c} / \mathrm{C} 4$ increased to $0.66 \mathrm{~g} / \mathrm{l} / 0.11 \mathrm{~g} / \mathrm{l}$, respectively. However, following the $9^{\text {th }}$ plasmapheresis treatment was stopped and an immunoadsorption was initiated to limit both the loss of valuable serum proteins and the patient's exposure to foreign blood products. Prednisolone therapy could be tapered to a daily dose of 30 mg. Immunoadsorption was performed six times, at intervals of 2 to 4 days, using the "Immunosorba" system (Protein A column, Fresenius Medical Care). Under this therapy, clinical symptoms, renal function and laboratory parameters improved further, even normalised $(\mathrm{C} 3 \mathrm{c}$ 1.31 g/l, C4 0.32 g/l, dsDNA-Ab 106.4) Figure 1A-1C. Serum IgG levels were beneath the lower detection threshold now $(<3.00 \mathrm{~g} / \mathrm{l}$ [reference 7-16 g/l]), and CD4/CD8 ratio decreased to 0.89 thus reflecting both humoral and cellular immunodepression resulting in a reactivation of cytomegaly. At the $28^{\text {th }}$ gestation week, the patient delivered a healthy child without any complications. During the postpartum period, the daily prednisolone dose was further reduced, without clinical signs of relapse.

From these observations, we conclude that plasmapheresis and immunoadsorption might be beneficial therapeutic options in the treatment of pregnant patients with SLE, especially when SLE is refractory towards steroid treatment. Effective removal of pathogenic autoantibodies, thereby easing severe disease features as polyarthritis, nephritis and pericarditis, might avoid the need of cytotoxic drugs with subsequent impairment of the foetus.

\section{Discussion}

The association between frequency of SLE flares, lupus activity, respectively and pregnancy is not clear. Some studies were not able to detect differences in flare incidence or severity in pregnant SLE patients compared to matched non-pregnant control patients $[10,11]$, but other authors highlight to role of pregnancy for lupus exacerbation [12,13]. Moreover, it has been shown that pregnant SLE patients had an increased risk of pre-eclampsia, hypertension, obstetric or foetal complications like intrauterine growth retardation, intrauterine death and preterm delivery [14]. Disease activity normally determines the need of immunosuppressive therapy including steroids, hydroxychloroquine, azathioprine, cyclophosphamide, Mycophenolat
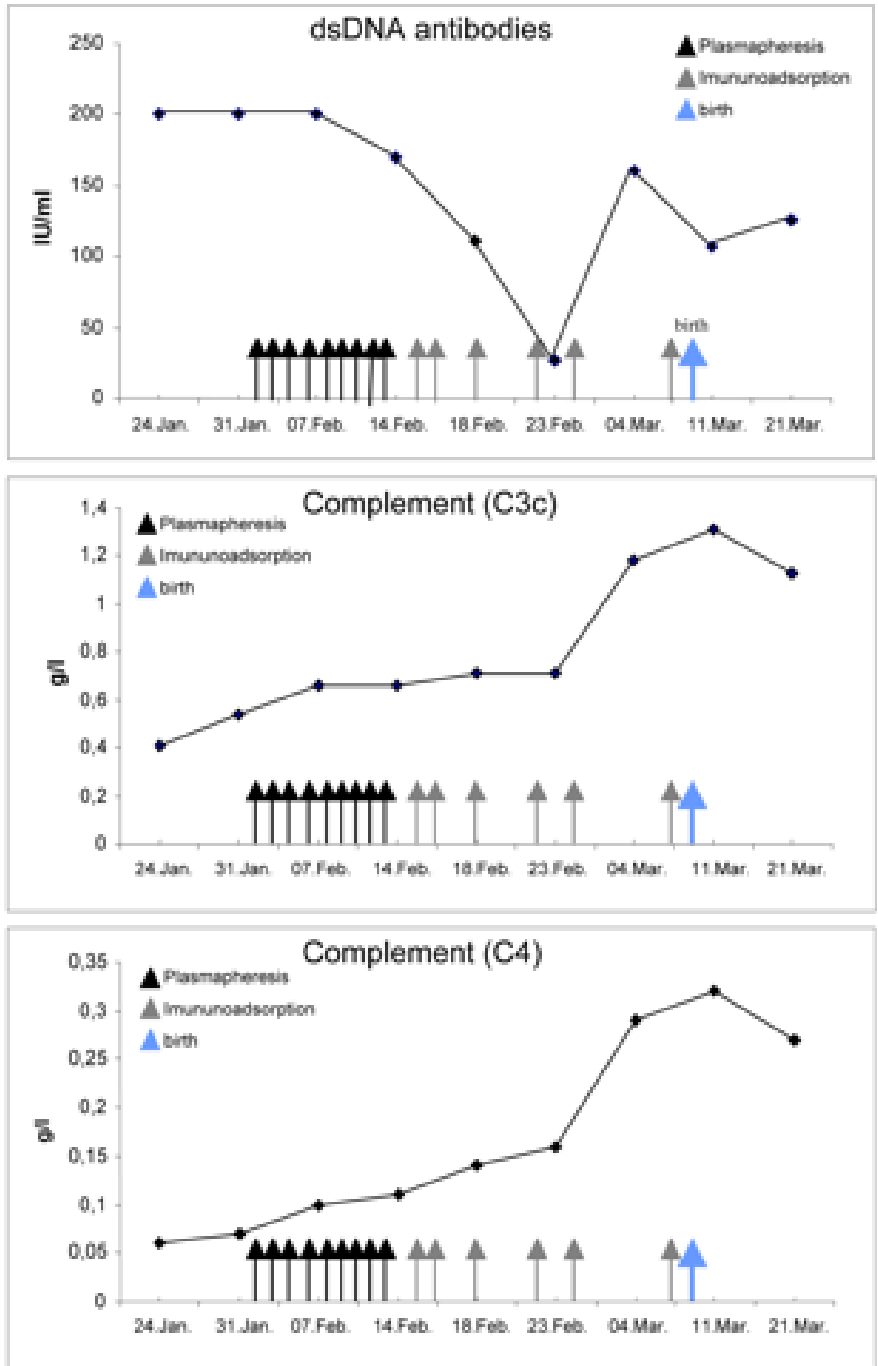

Figure 1. Graphs depicting the response of A) anti-ds/DNA antibodies; [reference $<35$ $\mathrm{IU} / \mathrm{ml}$ ], B) complement $\mathrm{C} 3 \mathrm{c}$; [reference $0.9-1.8 \mathrm{~g} / 1$ ] C) complement $\mathrm{C} 4$ [reference 0.1-0.4 $\mathrm{g} / \mathrm{l}]$, in response to plasmapheresis and immunoadsorption. The administration of a every 2 days plasmapheresis, later every 2-4 days immunoadsorption resulted in a continuous amelioration of SLE

mofetile (MMF), Cyclosporine and others. As therapy strategies have to consider both maternal and foetal aspects, pharmacotherapy is limited in pregnant SLE patients. Plasmapheresis and immunoadsorption provide alternative therapeutic options, particularly when conventional corticosteroid therapy is inefficient and other cytostatic therapies (MMF, cyclophosphamide, azathioprine etc.) either affect gestation or do not have an acute effect. Other new biologicals targeting cytokines and lymphocytes, like monoclonal anti-CD20, might be effective as well, but underlying mechanisms are not completely understood, and possible detrimental effects of these substances during pregnancy are not ruled out.

Up to now, no remarkable side effects have been attributed to plasmapheresis and immunoadsorption [15]. Plasmapheresis is able to remove free antibodies, circulating immune complexes and other components which are implicated in the pathogenesis of SLE from the patient's circulation, but the exact mechanisms still remain unclear. In recent years, the role of plasmapheresis in SLE patients has been estimated contradictory. Some authors reported beneficial effects of 
plasmapheresis in SLE patients, but the data mostly derived from noncontrolled or retrospective studies [16]. Moreover, beneficial removal of antibodies, circulating complexes etc. might be counteracted by antibody rebound which occurs after cessation of plasmapheresis treatment, if it has not been combined with immunosuppressive therapy $[15,16]$. Plasmapheresis is not a curative approach but might be useful as an adjunctive therapy during acute phases of disease, especially in patients with limited therapeutic options, like in pregnancy, children, or when conventional therapy failed. In some cases, plasmapheresis combined with glucocorticoids was able to prevent the development of congenital heart block in pregnant SLE patients [17] and has shown to ease the management of pregnant patients with acute SLE flares $[9,18,19]$.

During plasmapheresis, removed plasma has to be substituted with fresh frozen plasma to avoid bleeding complications, as the protein elimination is unspecific and essential plasma proteins, like coagulations factors, are removed as well. In immunoadsorption, protein elimination is more selectively, thus avoiding the administration of fresh frozen plasma. The development of new membranes from dextran sulphate, protein A-silica or -sepharose, tryptophan, phenylalanine, and IgThersorb columns, might enhance effectivity and selectivity of protein removal and prevent the rebound effects observed after plasmapheresis therapy $[16,20]$. Preliminary data showed that immunoadsorption improved the pregnancy outcome in patients with SLE, particularly without increased steroid dosage, but mostly, positive effects occurred when immunoadsorption was coupled with immunosuppressive therapy $[15,21]$. No side effects have been identified, so that immunoadsorption has been described to be safe when performed in pregnant SLE patients or pregnant patients with other autoimmune disease patients $[9,22,23]$.

\section{Conclusion}

Despite these encouraging observations, experience with plasmapheresis and immunoadsorption in pregnant SLE patients is still limited. Further studies must be performed to clarify if plasmapheresis or immunoadsorption could be established as appropriate and beneficial therapeutic options in these patients, either in addition to or even instead of conventional pharmacological strategies.

\section{References}

1. Rosner S, Ginzler EM, Diamond HS, Weiner M, Schlesinger M, et al. (1982) A multicenter study of outcome in systemic lupus erythematosus. II. Causes of death. Arthritis Rheum 25: 612-617. [Crossref]

2. Ginzler EM, Diamond HS, Weiner M, Schlesinger M, Fries JF, et al. (1982) A multicenter study of outcome in systemic lupus erythematosus. I. Entry variables as predictors of prognosis. Arthritis Rheum 25: 601-611.

3. Davidson JE, Fu Q, Ji B, Rao S, Roth D, et al. (2018) Renal remission status and longterm renal survival in patients with lupus nephritis: A retrospective cohort analysis. J Rheumatol 45: 671-677.

4. Molino C, Fabbian F, Longhini C (2009) Clinical approach to lupus nephritis: recent advances. Eur J Intern Med 20: 447-453.

5. Looney RJ, Anolik J, Sanz I (2004) B lymphocytes in systemic lupus erythematosus: lessons from therapy targeting B cells. Lupus 13: 381-390.
6. Felten R, Dervovic E, Chasset F, Gottenberg JE, Sibilia J, et al. (2018) The 2018 pipeline of targeted therapies under clinical development for Systemic Lupus Erythematosus: a systematic review of trials. Autoimmun Rev 17: 781-790.

7. Yan Yuen S, Krizova A, Ouimet JM, Pope JE (2008) Pregnancy outcome in systemic lupus erythematosus (SLE) is improving: Results from a case control study and literature review. Open Rheumatol J 2: 89-98.

8. de Jesus GR, Mendoza-Pinto C, de Jesus NR, Dos Santos FC, Klumb EM, et al. (2015) Understanding and managing pregnancy in patients with lupus. Autoimmune Dis 2015: 943490. [Crossref]

9. Dittrich E, Schmaldienst S, Langer M, Jansen M, Horl WH, et al. (2002) Immunoadsorption and plasma exchange in pregnancy. Kidney Blood Press Res 25: 232-239.

10. Lockshin MD, Reinitz E, Druzin ML, Murrman M, Estes D (1984) Lupus pregnancy. Case-control prospective study demonstrating absence of lupus exacerbation during or after pregnancy. Am J Med 77: 893-898. [Crossref]

11. Urowitz MB, Gladman DD, Farewell VT, Stewart J, McDonald J (1993) Lupus and pregnancy studies. Arthritis Rheum 36: 1392-1397. [Crossref]

12. Cervera R, Font J, Carmona F, Balasch J (2002) Pregnancy outcome in systemic lupus erythematosus: good news for the new millennium. Autoimmun Rev 1: 354-359.

13. Huong DL, Wechsler B, Vauthier-Brouzes D, Beaufils H, Lefebvre G, et al. (2001) Pregnancy in past or present lupus nephritis: A study of 32 pregnancies from a single centre. Ann Rheum Dis 60: 599-604. [Crossref]

14. Bramham K, Hunt BJ, Bewley S, Germain S, Calatayud I, et al. (2011) Pregnancy outcomes in systemic lupus erythematosus with and without previous nephritis. $J$ Rheumatol 38: 1906-1913.

15. Nakamura Y, Yoshida K, Itoh S, Kanai Y, Tsuda H, et al. (1999) Immunoadsorption plasmapheresis as a treatment for pregnancy complicated by systemic lupus erythematosus with positive antiphospholipid antibodies. Am J Reprod Immunol 41: 307-311.

16. Pagnoux C, Korach JM, Guillevin L (2005) Indications for plasma exchange in systemic lupus erythematosus in 2005. Lupus 14: 871-877. [Crossref]

17. Yang CH, Chen JY, Lee SC, Luo SF (2005) Successful preventive treatment of congenital heart block during pregnancy in a woman with systemic lupus erythematosus and anti-Sjogren's syndrome A/Ro antibody. J Microbiol Immunol Infect 38: 365-369.

18. Stummvoll GH, Aringer M, Smolen JS, Schmaldienst S, Jiménez-Boj E, et al. (2005) IgG immunoadsorption reduces systemic lupus erythematosus activity and proteinuria: A long term observational study. Ann Rheum Dis 64: 1015-1021. [Crossref]

19. Stummvoll GH, Schmaldienst S, Smolen JS, Derfler K, Biesenbach P (2012) Lupus nephritis: prolonged immunoadsorption (IAS) reduces proteinuria and stabilizes global disease activity. Nephrol Dial Transplant 27: 618-626.

20. Biesenbach P, Schmaldienst S, Smolen JS, Horl WH, Derfler K, et al. (2009) Immunoadsorption in SLE: three different high affinity columns are adequately effective in removing autoantibodies and controlling disease activity. Atheroscler Suppl 10: $114-121$.

21. Kronbichler A, Brezina B, Quintana LF, Jayne DR (2016) Efficacy of plasma exchange and immunoadsorption in systemic lupus erythematosus and antiphospholipid syndrome: A systematic review. Autoimmun Rev 15: 38-49.

22. Bambauer R, Latza R, Bambauer C, Burgard D, Schiel R (2013) Therapeutic apheresis in autoimmune diseases. Open Access Rheumatol 5: 93-103.

23. Hoffmann F, Kraft A, Heigl F, Mauch E, Koehler J, et al. (2018) Tryptophan immunoadsorption during pregnancy and breastfeeding in patients with acute relapse of multiple sclerosis and neuromyelitis optica. Ther Adv Neurol Disord 11: 1756286418774973

Copyright: (C2018 Boedecker S. This is an open-access article distributed under the terms of the Creative Commons Attribution License, which permits unrestricted use, distribution, and reproduction in any medium, provided the original author and source are credited. 